\title{
Bi-level home ventilators for non invasive positive pressure ventilation
}

\author{
R. Scala
}

\begin{abstract}
Bi-level home ventilators for non invasive positive pressure ventilation. $R$. Scala.

With the widespread use of non-invasive positive pressure mechanical ventilation, great efforts have been made to produce machines, the bi-level home ventilators, which are less sophisticated, cheaper and able to better compensate air leaks with respect to the domiciliary volume-target machines and the traditional ventilators used in intensive care unit. As consequence of quick technolog-
\end{abstract}

ic evolution, bi-level home ventilators may be nowadays successfully applied for both the non-invasive ventilatory domiciliary treatment of chronic respiratory failure and the management of acute respiratory failure especially outside the intensive care setting.

In this paper, the author describes the technical aspects, the individual characteristics and the clinical applications of the most common used bi-level ventilators.

Monaldi Arch Chest Dis 2004; 61: 4, 213-221.

Keywords: Non invasive positive pressure ventilation, home ventilators, bi-level ventilators, intensive care unit ventilators, trigger, humidifier.

Unità Operativa di Pneumologia, ASL8, Ospedale S. Donato, Arezzo.

Correspondence: Raffaele Scala; Via Cadutisul Lavoro, 8; 52100 Arezzo, Italy; e-mail: raffaele_scala@hotmail.com

\section{Introduction}

Home ventilators (HV) have been initially designed for long-term ventilatory support, mainly delivered non-invasively, to patients with chronic respiratory failure $(\mathrm{CRF})$. In the home care of CRF non-invasive positive pressure ventilation (NIPPV) has progressively taken over negative pressure ventilatory techniques (i.e. poncho and cuirass) which are less tolerated and transportable and may cause obstructive sleep apnoea [1]; so the employment of domiciliary negative pressure ventilators is today restricted to patients who cannot tolerate NIPPV [2].

The first HV used for NIPPV were the portable volume-target ventilators, previously built for domiciliary invasive mechanical support of ventilator-dependent patients. As well as in assistedcontrolled volume-target mode (ACV), these ventilators could work in synchronised intermittent mandatory mode (SIMV) which has the disadvantage of the increase in work of breathing during spontaneous ventilation, and, in some machines, in pressure-target modes. Even if well equipped with alarms, monitoring system and inner battery, these portable volume-target ventilators have some important limits especially for NIPPV: incapability to compensate air leaks; lack of positive end-expiratory pressure (PEEP), applicable only with an external valve which may interfere with inspiratory trigger sensitivity; high costs [3]. Their application as NIPPV is today limited to selected cases of CRF due to neuromuscular disorders [4].

To overcome the limitations of the volume-target $\mathrm{HV}$, since the beginning of the 1980s bi-level ventilators, whose prototype is the BiPAP, have been constructed especially with the aim of compensating air leaks during NIPPV [5]. The first bilevel HV have the following features which may specifically meet the needs of non-invasive domiciliary support in non-ventilator dependent CRF patients: easy handling, transportability, essential alarm and monitoring systems, low costs [3]. The name "bi-level ventilators" comes from their capability of non-invasively supporting the spontaneous breathing by the application of two different pressures: an inspiratory positive airway pressure (IPAP) to assist inspiration and a lower expiratory positive airway pressure (EPAP) to offset intrinsic PEEP in COPD, to recruit under-ventilated lung units, to minimise $\mathrm{CO}_{2}$-rebreathing [6]. With the growing interest on NIPPV in the acute respiratory failure (ARF), the technologic evolution has produced newer bi-level ventilators which, by overcoming some limitations of the first bi-level HV in the "acute" setting, could be effectively applied not only for home care but also for "acute" patients especially outside an intensive care setting $[3,6]$. On the other hand, newer algorithms for NIPPV were recently implemented in some intensive care unit ventilators (ICUV) which become particularly efficient in supporting non-invasively patients with severe ARF [3]. Finally, new sophisticated machines, called "intermediate ventilators", which combine some features of bi-level $\mathrm{HV}$, volume-target HV and ICUV, have been recently introduced to facilitate the delivery of NIPPV in the acute and in chronic setting.

In this paper, the author describes the technical aspects (table 1), the individual characteristics and 
the clinical applications, according to the setting (home care or ARF) and the underlying disease, of the most common used bi-level HV.

\section{Technical aspects of bi-level home ventilators}

\section{Source of gases and power}

Differently from ICUV which use compressed medical gases at pressures above the atmospheric level, bi-level $\mathrm{HV}$ are provided with either a pushing-sucking pump or an electrically supplied turbine pump to pressurise the room air. However, the lack of compressed gases doesn't guarantee the stability of pressurisation [7].

First generation bi-level HV have limited power in generating inspiratory pressures; the BiPAP prototype assures a maximum IPAP of $20 \mathrm{cmH}_{2} \mathrm{O}$, which could be not enough in severe obesity or chest wall diseases [3]. In an experimental study on lung model, while the BiPAP prototype was able to deliver an adequate tidal volume $(\mathrm{Vt})$ in normal respiratory mechanics, its performance was worst when compliance and/or resistance of the respiratory system were pathologically altered [5]. Two further investigations on lung model demonstrated that several bi-level HV were able to cope with high ventilatory demands showing at least the same performance of some ICUV [8,9]. In another experimental study [10], the tested bilevel HV worked as well as one ICUV but resulted in less efficiency than other two ICUV. Bi-level HV showed their own technical behaviour on a lung model [11, 12]; in a study "in vivo", Vitacca et al. [13] recently did not find substantial differences among 5 newer bi-level $\mathrm{HV}$ in terms of medium airway pressure, minute ventilation, unloading of respiratory muscles except for patient's comfort which was higher in four of the examined machines.

Despite the performance of several bi-level $\mathrm{HV}$, especially of recent production, may not be poorer than that of at least some ICUV from a technical point of view, the choice of a ventilator for NIPPV administration in the clinical ground is driven in each situation by further aspects (acute or chronic decompensation, setting of application, severity of ARF, underlying disease etc.) $[6,14]$.

\section{Oxygen supplement}

Bi-level HV are not generally provided with a blender where oxygen and room air are variably mixed making the inspiratory fraction of $\mathrm{O}_{2}\left(\mathrm{FiO}_{2}\right)$ to be controlled and stabilised [15]. In bi-level HV oxygen comes from low pressure sources and is delivered in different ways [1,7]: 1) at the level of either the ventilator or the circuit (at the proximal tip of the tube) or the mask; 2$)$ inside the pump $\left(\mathrm{FiO}_{2}\right.$ could be calculated with a normogramme during controlled volume-target ventilation); 3) inside the ventilator with a concentration modified by an electromagnetic valve $\left(\mathrm{FiO}_{2}\right.$ is detected by a sensor).

Variability of breathing pattern and air leaks during NIPPV make $\mathrm{FiO}_{2}$ unstable with bi-level
HV. This may not be a matter for patients who don't require $\mathrm{O}_{2}$ enrichment (i.e. CRF due to restrictive defects); in the opposite, ventilators with blender for $\mathrm{O}_{2}$ (i.e. ICUV or newer bi-level as BiPAP Vision) are recommended for sicker ARF patients especially in case of severe hypoxemia [3].

\section{Circuit}

The majority of first generation bi-level HV, as natural evolution of continuous positive airway pressure (CPAP), are provided with a single-tube circuit and the exhalation of expired air may occur through [7]:

a) a non-rebreathing expiratory valve ("mushroom" or "diaphragm" valve), situated in the circuit proximally respect the interface;

b) an unidirectional exhalation system (plateau exhalation valve), situated in the circuit proximally respect the interface; in this device a diaphragm limits air leaks during the inspiration and allows an unidirectional air flow during the expiration;

c) a non-valve exhalation system represented by an expiratory port which could be situated either in the circuit proximally respect the interface or directly inside the mask (i.e. whisper). The non-rebreathing valves allow a full exhalation of the expiratory air; nevertheless, they may increase the expiratory resistances. Lofaso et al. $[8,16]$ demonstrated in an experimental model an increase in expiratory work from 2 to 5 times with these valves compared to the whisper. Although significant clinical repercussions have not been demonstrated with non-rebreathing valves, an increase in expiratory resistances could negatively affect patient-ventilator synchrony [3, 7].

By applying a whisper, $\mathrm{CO}_{2}$ removal is influenced by both the expiratory flow and the level of PEEP applied; in fact with low PEEP $\left(<4 \mathrm{cmH}_{2} \mathrm{O}\right)$ the rate of rebreathing increases when the expiratory flow of the patient overcomes the maximum power of the exhalation system [17], reaching the $55 \%$ of the $\mathrm{Vt}$ with PEEP $2 \mathrm{cmH}_{2} \mathrm{O}$, IPAP 10 $\mathrm{cmH}_{2} \mathrm{O}$ and respiratory rate (RR) $15 /$ minute [16]. In intubated patients, compared to an ICUV, BiPAP equipped with a whisper and set at low levels of PEEP was associated with an higher work of breathing due to rebreathing even if any significant differences in blood gases were not observed [16]. A full wash-out of $\mathrm{CO}_{2}$ using a whisper is demonstrated only for PEEP $\geq 8 \mathrm{cmH}_{2} \mathrm{O}$, not easily tolerated and rarely needed with NIPPV. The plateau exhalation valve is the unique demonstrated system able to allow a complete $\mathrm{CO}_{2}$ removal with a single-tube circuit bi-level HV independently on the level of PEEP applied [17]. Recently, it has been shown on a lung model that rebreathing was significantly lower with a facial mask equipped with an expiratory port than with the same mask and a whisper inserted in the circuit [18].

Similarly to all ICUV, some newer bi-level HV have a double-tube circuit in whom a complete separation exists between inspiratory and expiratory lines without any risk of rebreathing. 
As well as single and double-tube circuit, two "intermediate ventilators" (I-Vent201, Breas LTV 1000) were equipped with an "incomplete doubletube circuit", where the expiratory limb is composed only of a short tube with a PEEP valve.

\section{Inspiratory and expiratory trigger}

Trigger optimises patient-ventilator interaction through the detection of inspiratory effort (inspiratory trigger) and, during pressure support ventilation (PSV), through the tuning of inspiratory-expiratory cycling (expiratory trigger). The opportunity of setting trigger's sensitivity may improve patient-ventilator synchrony and comfort of the patient during NIPPV, even though a direct impact upon short and long term outcome hasn't been demonstrated.

Inspiratory trigger should be set at the higher sensitivity capable of reducing the work of breathing and preventing wasted efforts. During NIPPV with a too sensitive trigger, especially if flowbased, air leaks may induce auto-activation of the ventilator and, consequently, patient-ventilator dyssynchrony [3]. Inspiratory trigger of bi-level HV may work at flow, pressure or volume depending on the way the spontaneous activity of the patient is recognised. Mixed inspiratory triggers (i.e. flow and pressure) are implemented in some ventilators, where it's possible to tune both parameters to set the sensitivity of the trigger. It has been demonstrated that flow triggers are associated with lower inspiratory work with respect to pressure triggers during NIPPV delivered both in PSV or ACV [19].

Expiratory trigger optimises the synchrony between the inspiratory time of the patient and of the machine. During PSV, cycling to expiration is flow-dependent in relation with a threshold value [7]. Under NIPPV air leaks may delay or avoid the inspiratory flow to reach the threshold with dyssynchrony ("inspiratory hung up"). The chance of setting the threshold value and/or the maximum inspiratory time, the availability of special algorithms, the use of assist-controlled pressure target mode (ACPV), in which expiratory cycling is time-dependent, may prevent this phenomenon [7, 20]. With some ventilators the physician has the option to set the expiratory trigger in "auto function", which means that the end of the inspiration is optimised breath per breath by special algorithms designed for NIPPV to minimise any dyssynchrony mainly due to air leaks.

In some recently produced bi-level $\mathrm{HV}$, the physician may set the sensitivity of both inspiratory and expiratory trigger; it should be take in mind that different bi-level HV have different and not comparable levels of sensitivity of trigger's system [21].

\section{Inspiratory flow}

With most of first-generation bi-level HV it's not possible to set the inspiratory flow. The opportunity of setting the rise time in the newer bi-level
HV may improve patient's interaction with the ventilator and his comfort even if an effect upon the outcome hasn't been shown neither in acute nor in chronic setting. However, severely dyspnoeic COPD patients cope better with higher flow (rise time of 0.05-0.1 seconds), while neuromuscular patients do better with lower flow (rise time of 0.3-0.4 seconds) [3].

\section{Back-up respiratory rate}

Some of bi-level HV do not have the option of setting a back-up RR, which therefore raises the cost of the ventilator. There are not substantial data until now documenting the real usefulness of setting this parameter both in ARF and in CRF; on the other hand, it may not be excluded its utility in certain circumstances. In severe stable COPD no difference in terms of blood gases was found whether NIPPV was applied with or without a back-up RR [22]. However, setting this parameter could be useful in acute patients with instable breathing pattern (even though in this case the conventional ventilation via an endotracheal tube is strongly recommended), as well as in CRF patients due to neuromuscular disorders (i.e. amyotrophic lateral sclerosis) in whom an high back-up RR (2024/minute) may allow a full control of their breathing especially during the sleep [23].

\section{Humidification}

Although the nose acts as a natural humidifier of inspiratory gases, pharyngeal and nasal dryness and thickness of secretions involve up to $40 \%$ of patients in NIPPV. Moreover during nasal ventilation air leaks through the mouth may increase nasal resistances [24]. Heated humidifiers (HH) have greater clinical advantages even though they require an higher amount of work by nurses or familiars to be managed with respect to heat-moisture exchangers (HME). The latter increase the expiratory load and may interfere with patient-ventilator synchrony [3]; moreover, according to recent investigations "in vivo", NIPPV is less effective in unloading respiratory muscles if applied with HME, due to its additional dead space, instead of $\mathrm{HH}[25,26]$. However, physician should not forget the risk of ventilator malfunction connected with the use of $\mathrm{HH}$ with single-tube circuit bi-level HV due to the possibility of water recoil into the circuit and into the expiratory valve.

\section{Inner battery}

The lack of an inner battery makes most of bilevel HV unsuitable and unsafe for patients who require a continuous domiciliary mechanical support or need to be transported. An external battery (autonomy up to 8 hours) may be added to some of these HV, even though it makes them too heavy [3].

The choice of HV with or without an inner battery should be guided by the type of the ventilated patient who needs a domiciliary mechanical support. 


\section{Alarm and monitoring systems}

The prototype of BiPAP do not have either alarm or monitoring features [5], with an advantage in costs and transportability. In non ventilatordependent CRF patients, who were already adapted to NIPPV, sophisticated monitoring may not be required at home and alarms may disturb the sleep interfering with patient's compliance [2]. Contrastly, during the hospital training of the patient candidate to home treatment, the availability of a bi-level HV with monitoring graphics (i.e. flow and pressure curves) may be helpful in optimising patient/ventilator interaction especially when no improvement in comfort or blood gases is found. Implementation of NIPPV to treat ARF is recommended only by means of bi-level HV with essential alarm and monitoring systems helpful to improve patient-machine synchrony. For these reasons, as all ICUV, most of recently produced bilevel HV are provided with more sophisticated alarms (disconnection from the ventilator, low and high pressure, low and high Vt and/or RR, air leaks) and monitoring equipment. The importance for the physician to have a ventilator with a visual display of breathing pattern and flow-pressure curves is crucial in the "acute" patient. The key parameter to monitor NIPPV is the expiratory Vt as excessive air leaks may cause a significant discrepancy between inspiratory and expiratory $\mathrm{Vt}[3,7]$.

Single-tube circuit bi-level $\mathrm{HV}$ allow to monitor the inspiratory $\mathrm{Vt}$, which corresponds to the sum of the patient's Vt and the air leaks; as the inspiratory Vt increases for compensatory mechanism of sensible air leaks, it doesn't reflect directly minute ventilation. Estimation of expiratory Vt performed by some bilevel HV has not been validated [7].

Double-tube circuit bi-level $\mathrm{HV}$ allow to closely monitor the expiratory $\mathrm{Vt}$, whose value is more reliable with ventilators which make the measurement at the level of the expiratory branch of the Y-tube than with those which make the measurement in the inlet of the expiratory tube into the ventilator [27].

\section{Individual characteristics of bi-level home ventilators}

Most manufacturers have made tremendous efforts to address many of the technical limitations shown by the first pro- duced bi-level HV. Consequently, they have introduced and are still introducing in the market newer, more sophisticated and more expensive versions of their original machines. The aim is to offer to the physicians a great variety of ventilators which may match every need throughout the wide spectrum of potential clinical applications of NIPPV. Due to the huge and increasing number of different devices, in this section of the paper we will just report in the table 2 the main features of the most common used bi-level HV.

Even though there is not robust scientific evidence about the superiority of one machine compared to the others in each clinical applications, it's clear that easier and less equipped bi-level HV are more likely to be recommended in chronic setting for non ventilator-dependent patients, while more sophisticated and equipped bi-level are more likely to be applied in acute setting. The physician has to choose one ventilator in place of another depending on the technical features of the machine,
Table 1. - Technical aspects of bi-level home ventilators

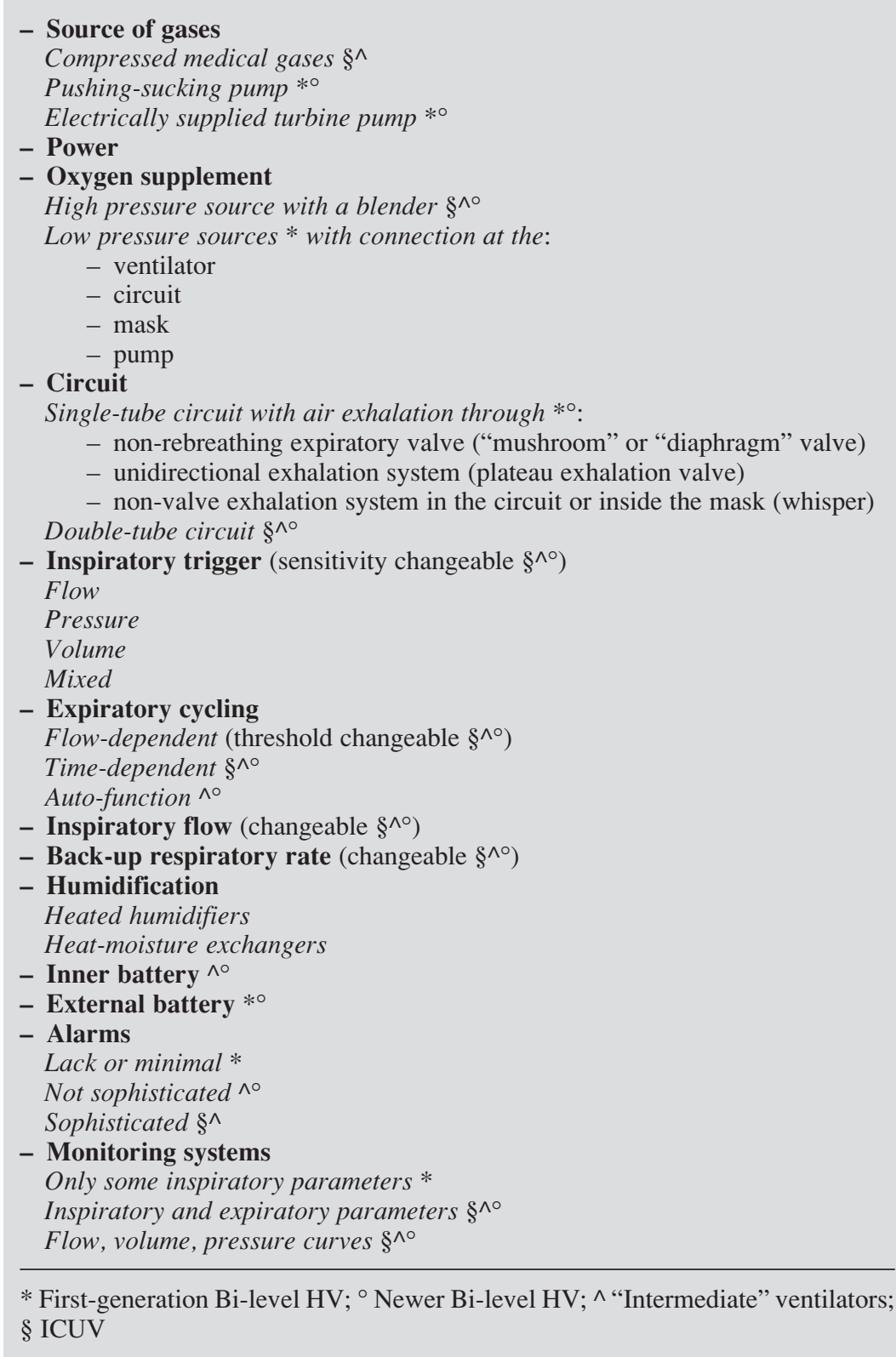


the patient's needs, and, not at last, his familiarity with the ventilator and the costs $[6,7,14,15]$.

\section{Clinical applications of bi-level home ventilators}

The choice of a ventilator for NIPPV should be driven by several points: setting (home support for CRF, hospital use for ARF), environment (ordinary or higher intensive level of care units) where to treat "acute" patients, severity of ARF, underlying disease, experience of the team.

Regarding the chronic setting, randomised, prospective controlled trial comparing bi-level HV over portable volume-limited ventilators are lacking. Restrick et al [22] found no difference in over night oxygenation with the use of pressure-support or volume-limited ventilators each for one night. In a series of 30 consecutive patients with mainly restrictive pattern of CRF, Schoenhofer et al [28] reported an higher rate of failure to improve hypercapnia when patients were administered nasal NIPPV in a ACPV mode than in ACV mode. On the other hand, Smith and Shneerson [11] observed improved daytime blood gases in 10 patients with CRF switched from portable volume-target to bilevel HV. Results of these available studies show no clear clinical superiority of one ventilator mode over the other, so the choice of bi-level ventilators depends on the evaluation of their specific advantages in each individual case [6].

As underlined, bi-level HV are more portable and less expensive, have better capacity in air leak's compensation and are provided with limited alarms that can needlessly interfere with sleep during transient air leaking. For these reasons they are usually recommended for patients with CRF requiring only nocturnal or partial daytime domiciliary NIPPV, when equipped with an adequate exhalation system for single-tube circuit. Volumelimited HV may be preferred to bi-level HV for CRF in patients with little spontaneous breathing capability (i.e. neuromuscular disorders) who can "stack" breaths to achieve larger Vt increasing airflow and expectoration during cough; they have the advantage of ensuring alveolar ventilation when mechanics of respiratory system changes [14]. These ventilators are well suited also for patients requiring home continuous ventilatory support or needing higher inflation pressures (i.e. severe chest wall deformity, obesity) [6]. However, with the implementation of specific technical features (power in generating higher pressures, double tube circuit, built-in backup battery, more sophisticated alarm and monitoring system), newer bi-level ventilators seems to be useful for most of the clinical applications in chronic setting. In particular, the capability of assuring a target Vt with the volume-assured pressure support mode (VAPS) [29] in some newer bi-level HV makes less strong the boundaries between pressure-target and volume-target NIPPV; moreover, in some of these machines volume-target modes of ventilation are implemented together with bi-level ones.
In ARF NIPPV delivered both in pressure-target and volume-target has shown to be effective [6, 30]. Few comparative studies failed to find any differences in clinical outcome and blood gases in COPD exacerbations ventilated with PSV or ACV $[31,32]$. Although both modalities improved breathing pattern and respiratory muscle rest, $\mathrm{ACV}$ produced a lower respiratory workload at the cost of greater patient's discomfort and less ability to compensate for mask leaks respect PSV [31, 33]. According to BTS guidelines for NIPPV [14], bi-level is probably the preferred mode of ventilation for most of the patients with COPD exacerbation. ACV could be necessary for patients with non-COPD diseases who are likely to make little effort (i.e. neuromuscular diseases).

Regarding the type of machine used, clinical outcome studies using bi-level HV reported similar success rate than that obtained with ICUV in COPD exacerbations, but no controlled trial has directly compared the two devices $[14,30]$. As described above, performance characteristics of at least some bi-level HV compare favourably with those of some ICUV. Use of simple bi-level HV for treat ARF in a respiratory ward with nasal or facial mask should be reserved to the early phase of COPD exacerbations. Patients with severe ARF, especially if hypoxemic (in whom the rate of failure of NIPPV is higher), who require high $\mathrm{FiO}_{2}$ or are dependent on continuous ventilatory support should be managed in an intensive care level setting by means of ICUV with specific algorithms (i.e. Puritan Bennet 8400) for NIPPV through a facial mask as these machines show potential advantages over bi-level HV (oxygen blender, inspiratory and expiratory cycling, sophisticated alarms, monitoring of respiratory mechanics, availability of both pressure-target and volume-target modes) [34]. The prompt availability of intubation in case of failure makes the NIPPV trial in ICU safer for more critical patients [30].

However, with the newer bi-level machines, provided with several technical features aimed at enhancing patient comfort and patient-machine synchrony (i.e. oxygen blender, double tube circuit, alarm and monitoring systems, VAPS), it's possible to manage several ARF cases mainly with facial mask in a setting different from the respiratory ward.

Intermediate ventilators, designed to bridge the gap between bi-level HV and ICUV, may deliver both pressured and volume-target ventilations, but none has the leak compensation capabilities of the bi-level HV; their place in NIPPV is not clear but probably they may be suitable for treating different kind of diseases in ARF and CRF.

In absence of a strong evidence toward a specific bi-level HV and modality of NIPPV, the choice of a device should take in consideration local expertise and familiarity of the team and should be tailored to the aetiology, the severity and the pathophysiology of the acute or chronic disorder. It must be borne in mind that more sophisticated options available in a ventilator require more 


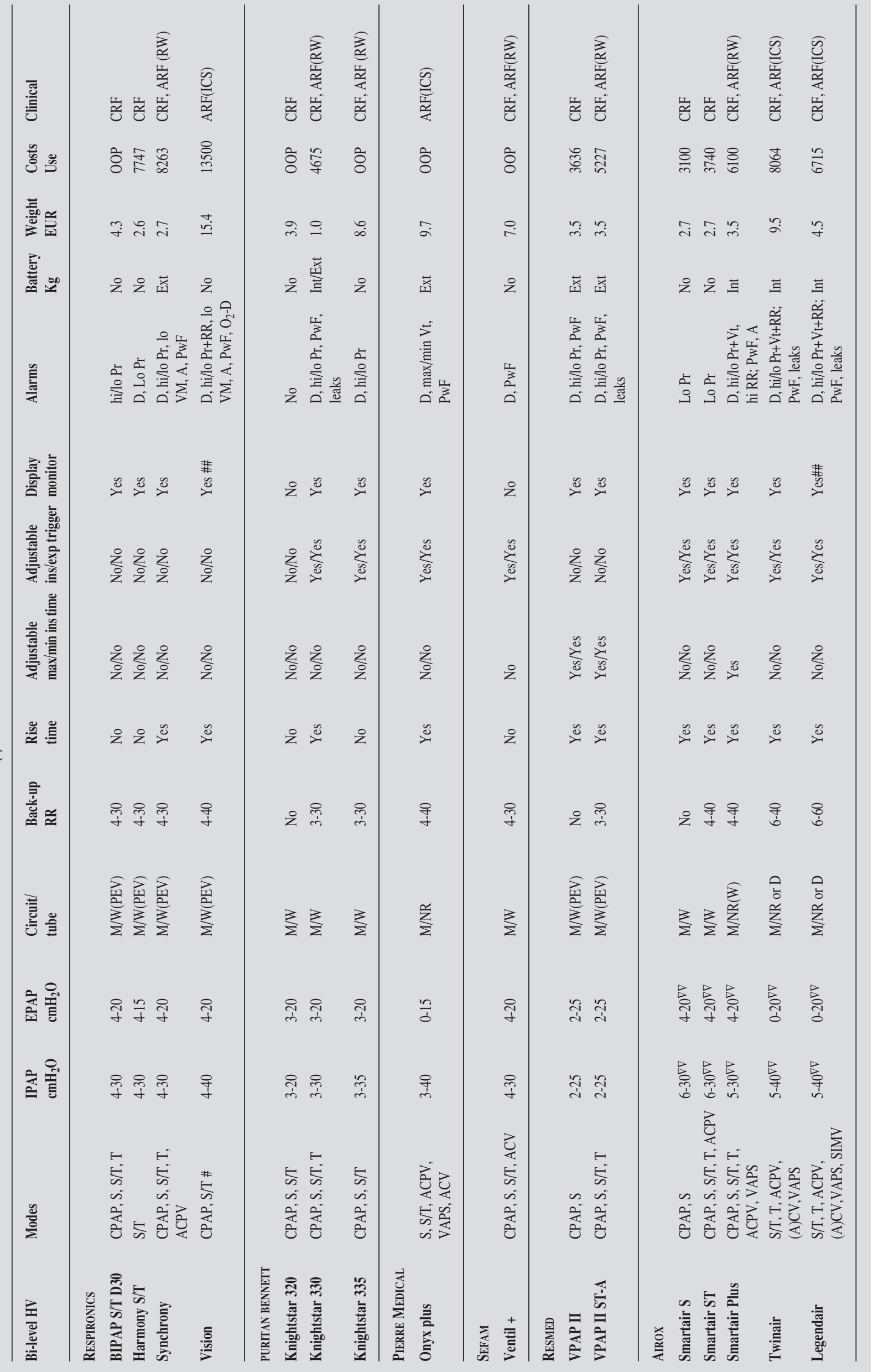




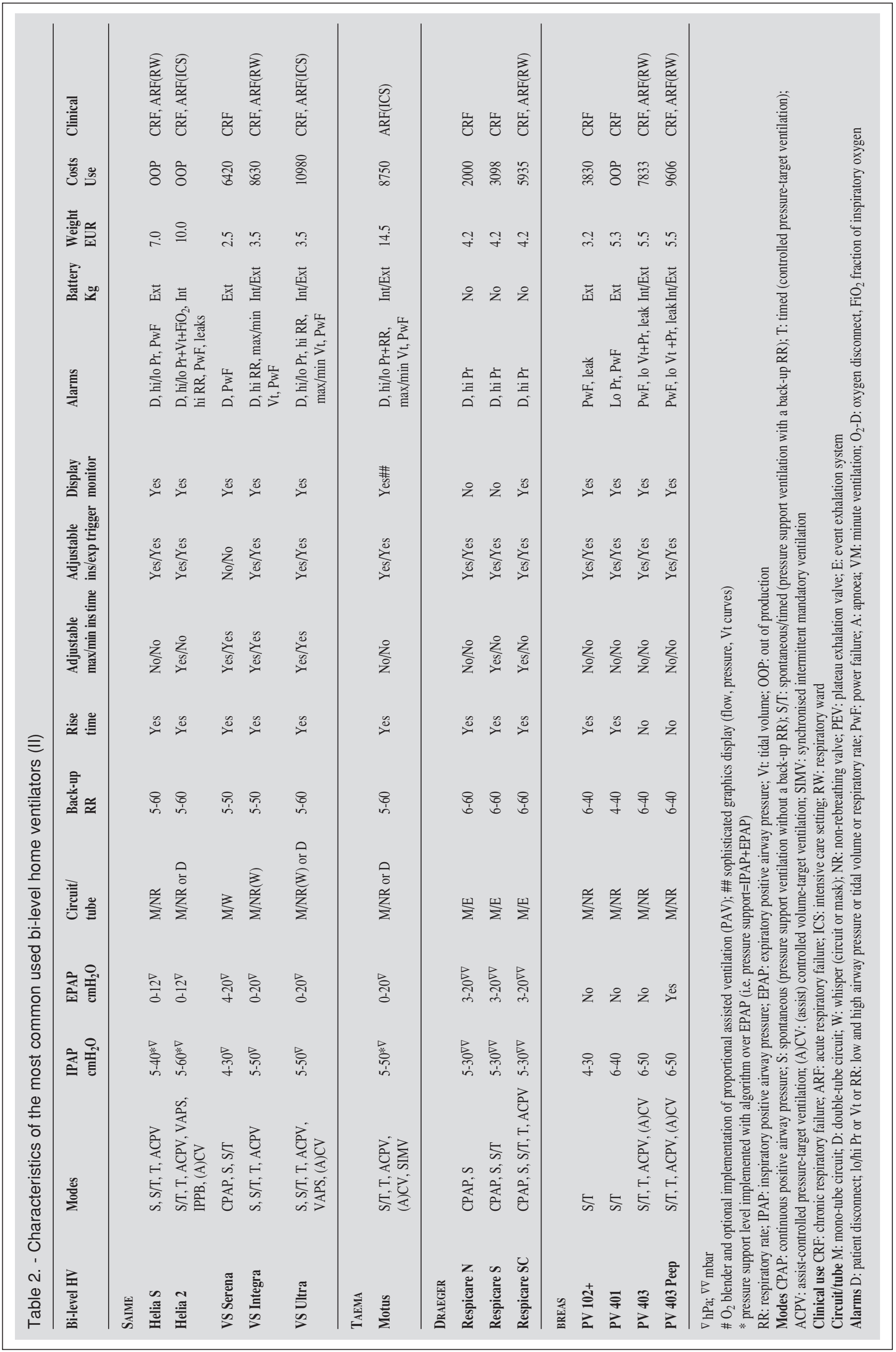


physician understanding although they may increase the comfort of the patient and possibly the outcome.

\section{Conclusions}

The application of NIPPV for home care of CRF and for hospital management of ARF outside an intensive care setting [6] has given a significant stimulus to the technological evolution of bi-level HV. Type of patient, application at home or in "acute" setting, severity of ARF, training of nurse and familiars, costs and patient's comfort are the main factors which have to be considered in the choice of the most suitable bi-level HV for NIPPV.

\section{References}

1. Kacmarek RM, Hess DR. Equipment required for home mechanical ventilation. In: Tobin MJ, ed Principles and Practice of Mechanical Ventilation. New York, McGraw Hill Pub, 1994: 111-115.

2. Ambrosino N, Clini E, Gigliotti F, Lanini B, Vianello A. Raccomandazioni per la ventilazione meccanica domiciliare. Aggiornamento anno 2003. Parte 1. Rassegna di Patologia dell'Apparato Respiratorio 2003; 18: 368-375.

3. Kacmarek RM, Hill NS. Ventilators for noninvasive positive pressure ventilation: technical aspects. Eur Respir Mon 2001; 16: 76-105.

4. Bach JR, Alba AS, Saporito LR. Intermittent positive pressure ventilation via mouth as an alternative to tracheostomy for 257 ventilator users. Chest 1993; 103: 174-182.

5. Strumpf DA, Carlisle CC, Millman RP et al. An evaluation of the Respironics Bi-PAP bi-level CPAP device for delivery assisted ventilation. Respir Care 1990; 35: 415-422.

6. Metha S, Hill NS. Noninvasive ventilation. Am J Respir Crit Care Med 2001; 163: 540-577.

7. Navalesi P, Confalonieri M, Corbetta L, Gorini M, Gregoretti C, Corrado A. I ventilatori nell'unità di terapia intensiva pneumologica. Rassegna di Patologia dell'Apparato Respiratorio 1999; 14: 206-214.

8. Lofaso F, Brochard L, Thierry H, Hubert L, Haref A, Isabey D. Home versus intensive care pressure support devices. Experimental and clinical comparison. Am J Respir Crit Care Med 1996; 153: 1591-1599.

9. Bunburaphong T, Imaka H, Nishimura M, Hess D, Kacmarek RM. Performance characteristics of bilevel pressure ventilators. A lung model study. Chest 1997; 111: 1050-1060.

10. Tassaux D, Strasser F, Fonseca S, Dalmas E, Jolliet P. Comparative bench study of triggering, pressurization and cycling between the home ventilator VPAP II and three ICU ventilators. Intens Care Med 2002; 28: 1254-1261.

11. Smith IE, Shneerson JM. A laboratory comparison of four positive pressure ventilators used in the home. Eur Respir J 1996; 9: 2410-2415.

12. Highcock MP, Shneerson JM, Smith IE. Functional differences in bi-level pressure preset ventilators. Eur Respir J 2001; 17: 268-273.

13. Vitacca M, Barbano L, D'Anna S, Porta R, Bianchi L, Ambrosino N. Comparison of five bilevel pressure ventilators in patients with chronic ventilatory failure: a physiologic study. Chest 2002; 122: 2105-2114.

14. Baudouin S, Blumenthal S, Cooper B et al. British Thoracic Society Guideline. Non-invasive ventilation in acute respiratory failure. Thorax 2002; 57: 192-211.
15. Kacmarek RM, Hess DR. Basic principles of ventilator machinery. In: Tobin MJ, ed Principles and Practice of Mechanical Ventilation. New York, McGraw Hill Pub, 1994: 65-110.

16. Lofaso F, Brochard L, Touchard D, Hang T, Harf A, Isabey D. Evaluation of carbon dioxide rebreathing during pressure support ventilation with airway management system (BiPAP) devices. Chest 1995; 108: 772778.

17. Ferguson GT, Gilmartin $\mathrm{M} . \mathrm{CO}_{2}$ rebreathing during BiPAP ventilatory assistance. Am J Respir Crit Care Med 1995; 151: 1126-1135.

18. Schettino GP, Chatmongkolchart S, Hess DR, Kacmarek RM. Position of exhalation port and mask design affect $\mathrm{CO}_{2}$ rebreathing during noninvasive positive pressure ventilation. Crit Care Med 2003; 31: 2178-82.

19. Nava S, Bruschi C, Ambrosino N, Patruno V, Confalonieri $\mathrm{M}$. Inspiratory effort during non-invasive mechanical ventilation with flow and pressure triggers in COPD patients. Intens Care Med 1995; 21 (Suppl 1): S 120.

20. Calderini E, Confalonieri M, Puccio PG, Francavilla N, Stella L, Gregoretti C. Patient-ventilator asynchrony during noninvasive ventilation: the role of expiratory trigger. Intens Care Med 1999; 25: 662-667.

21. Hill NS, Metha S, Carlisle CC, McCool FD. Evaluation of the Puritan-Bennett 335 portable pressure support ventilator. Comparison with the Respironics BiPAP S/T. Respir Care 1996; 41: 885-894.

22. Restrick LJ, Fox NC, Braid G, Ward EM, Paul EA, Wedzicha JA. Comparison of nasal pressure support ventilation with nasal intermittent positive pressure ventilation in patients with nocturnal hypoventilation. Eur Respir J 1993; 6: 365-370.

23. Hill NS, Eveloff SE, Carlisle CC, Goff SG. Efficacy of nocturnal nasal ventilation in patients with restrictive thoracic disease. Am Rev Respir Dis 1992; 101: 516521.

24. Richards GN, Cistulli PA, Ungar RG, Berthon-Jones M, Sullivan CE. Mouth leak with nasal continuous positive airway pressure increases nasal airway resistance. Am J Respir Crit Care Med 1996; 154: 182-186.

25. Lellouche F, Maggiore SM, Deye N, Taille S, Pigeot J, Harf A, Brochard L. Effect of the humidification device on the work of breathing during non-invasive ventilation. Intens Care Med 2002; 28: 1582-1589.

26. Jaber S, Chanques $\mathrm{G}$, Matecki S, Ramonatxo M, Souche B, Perrigault PF, Eledjam JJ. Comparison of the effects of heat and moisture exchangers and heated humidifiers on ventilation and gas exchange during noninvasive ventilation. Intens Care Med 2002; 28: 15901594.

27. Nava S., Confalonieri M. Monitoraggio nella terapia intensiva respiratoria (UTIR). Rassegna di Patologia dell'Apparato Respiratorio 1996; 11: 169-175.

28. Schonhofer B, Sonneborn M, Haidl P, Bohrer H, Kohler D. Comparison of two different modes of noninvasive mechanical ventilation in chronic respiratory failure: volume versus pressure controlled devices. Eur Respir J 1997; 10: 184-191.

29. Amato MB, Barbas CS, Bonassa J, Saldiva PH, Zin WA, de Carvalho CR. Volume-assured pressure support ventilation (VAPSV). A new approach for reducing muscle workload during acute respiratory failure. Chest 1992; 102: 1225-1234.

30. International Consensus Conference in Intensive Care Medicine: Noninvasive positive pressure ventilation in Acute Respiratory Failure. Am J Respir Crit Care Med 2001; 163: 283-291.

31. Vitacca M, Rubini F, Foglio K, Scalvini S, Nava S, Ambrosino N. Non-invasive modalities of positive 
pressure ventilation improve the outcome of acute exacerbations in COLD patients. Intens Care Med 1993; 19: 450-455.

32. Meecham-Jones DJ, Paul EA, Grahame-Clarke C, Wedzicha JA. Nasal ventilation in acute exacerbations of chronic obstructive pulmonary disease: effect of ventilator mode on arterial blood gases tensions. Thorax 1994; 49: 1222-1224.

33. Girault C, Richard JC, Chevron V, Tamion F, Pasquis
P, Leroy J, Bonmarchand G. Comparative physiologic effects of noninvasive assist-control and pressure support ventilation in acute hypercapnic respiratory failure. Chest 1997; 111: 1639-1648.

34. Antonelli M, Conti G, Rocco M et al. A comparison of noninvasive positive pressure ventilation and conventional mechanical ventilation in patients with acute respiratory failure. $N$ Engl J Med 1988; 339: 429-435.

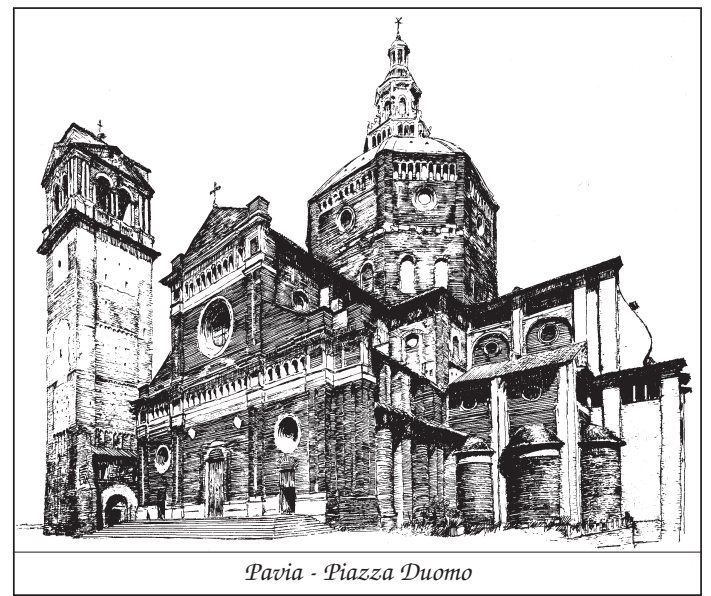

